\title{
DESAIN KONSEP PROTOTYPE ALAT PEMBUAT TELUR ASIN MENGGUNAKAN OPTIMALISASI COMPRESSED AIR
}

\author{
Sumadi $^{1 *}$,Budi Hartono ${ }^{1}$, Roy Waluyo ${ }^{1}$ \\ ${ }^{1}$ Fakultas Teknik dan Sains, Universitas Ibn Khaldun Bogor ,Indonesia, 1661
}

\begin{abstract}
ABSTRAK
Telur asin adalah merupakan makan budaya orang Indonesia yang sudah turun temurun,banyak cara yang digunakan untuk membuat telur asin, mulai dari menggunakan lumpur, direndam dalam air garam didalam toples.Konsep pembuatan telur asin yang umumnya dilakukan di masyarakat adalamenggunakan cara-cara tradsional, seperti merendam telur menggunakan lumpur dengan campuran garam, dengan cara pembuatan teluar asin seperti ini aktu produksi teluar asin mencapai 15 hari dan penelitian untuk mempercepat proses produksi telur asin terus dilakukan dengan metode menggunakan rekayasa udara bertekanan dengan umemasukan udara bertekanan, dengan cara ini proses produksi telur bisa lebih pendek hingga 1-2 hari, Artikel ini mengkaji sebuah konsep alat pembuat telur asin dengan menggunakan tekanan hidro-pneumatic, yaitu menggunakan optimalisasi compressed Air pada sebuah vessel horizontal dengan dimensi panjang $400 \mathrm{~mm}$, diameter $250 \mathrm{~mm}$, dengan manhole berada dibagian atas sebagai tempat pengisian dan pengambilan telur setelah proses selesai, diharapkan dengan metode ini waktu proses produksi telur asin akan menjadi 1-2 jam
\end{abstract}

Kata kunci : compressed air; horizontal vessel; hydro-pneumatic; optimalisasi, , waktu produksi.

\begin{abstract}
Salted eggs are a food for Indonesian culture that has been passed down from generation to generation, there are many ways used to make salted eggs, starting from using mud, soaking in salt water in a jar. The concept of making salted eggs which is generally practiced in the community uses traditional methods, such as Soaking eggs using mud with a mixture of salt, by making salted outer shells like this, the production of salted eggs is up to 15 days and research to speed up the process of salted egg production is continuously carried out by using the engineering method of compressed air by incorporating compressed air, in this way the egg production process can shorter to 1-2 days, this article examines the concept of a salted egg maker using hydro-pneumatic pressure, which is using compressed air optimization on a horizontal vessel with dimensions of $400 \mathrm{~mm}$ in length, $250 \mathrm{~mm}$ in diameter, with a manhole at the top as a place charging and taking eggs after the process is complete, it is hoped that with this method the production process time of salted eggs will be 1-2 hours
\end{abstract}

Keywords: compressed air; horizontal vessel; hydro-pneumatic; optimization; production time

* Penulis korespondensi
Email: sumadi@ft.uika-bogor.ac.id

Diterima 21 Desember 2020; Penerimaan hasil revisi 13 Februari 2021; Disetujui 17 Februari 2021

Tersedia online Maret 2021

AME (Aplikasi Mekanika dan Energi): Jurnal Ilmiah Teknik Mesin @) 2021 


\section{PENDAHULUAN}

Telur asin adalah sebuah makanan tradsional masyarakat indonesia dan paling digemari banyak orang, yang tentunya tak asing lagi pagi pencinta kuliner, rasanya berbagai macam, mulai dari terlur asin rasa bawang, telur asin rasa bawang pedas dan lain-lain, adapun cara membuat telur asinpun berbagai macam cara, mulai dari dengan cara metode abu gosok, metode batu bata (Brilio.Net), metode dengan cara merendam telur didalam air garam didalam toples (Titin Rayner), waktu rata-rata proses pembuatan telur asin adalah 10 hari -14 hari. Lamanya proses pembuatan telur asin ini melatarbelakangi pembuatan prototype alat pembuat telur asin.

Banyak para pemerhati dan peneliti telah mengkaji alat pembuat telur asin ini diantaranya adalah Joko Susilo, Juli 2017, SMA Negeri 1 Plupuh Seragen,Surakarta,dengan judul "Teknologi Pembuatan Telur Asin Selama 3 Jam Melalui Melalui modifikasi Tekanan Osmotik, konsep ini dilakukan dengan merendam telur dalam asam cuka agar dapat membuka membrane smipermeable pada kulit telur sehingga larutan telur cepat masuk dalam telur, hasilnya bisa mempersingkat proses pengasinan telur yaitu 3 Jam [1].

Peneliti lain yang telah melakukan kajian terhadap proses pembuatan telur asin ini adalah Sunyoto,Suwahyo,Meddiati Fajri Putri, Universitas Negeri Semarang, 2015, dengan

judul, “ Penerapan Iptek Pada Industri Kecil Pembuatan Telur Asin Khas Tambakrejo Kota Semarang, konsep ini dilakukan dengan merendam telur dalam air garam yang di masukan dalam tabung vertical dimana dalam tabung diletakan rak-rak, kemudian tabung diberi tekanan udara sebesar 1,5 $\mathrm{kg} / \mathrm{cm}^{2}$, dengan konsep ini proses pengasisnan telur bisa 1 hari -2 hari [3].

Tri Agus Susanto,Arthur Khalik Razak,Asywar Asywar, Maria Suryaningsih, Syamsul Syamsul, 2016, Jurnal Teknik Mesin,Jurusan Teknik Mesin, Politeknik Negeri Ujung Panang,dengan judul penelitian,'Rancang Bangun Alat Pembuat Telur Asin Dengan Pemanfaatan Udara, konsep ini adalah dengan menggunakan udara untuk melarutkan kadar garam melalui pori-pori telur, dengan konsep ini pengasinan telur bisa mempersingkat menjadi waktu 4 hari.[4]

A Engelen, S Umela, A A Hasan, Pengaruh lama pengasinan Pada Pembuatan Telur Asin Dengan Cara Basah, Poli Teknik Gorontalo, konsep menggunakan, Jurnal Argo Industry Halal ISSN 2442-3548 Volume 3 nomor 2,Februari 2017 [5]

Dewi Andriani, St. Hadijah, Uji Coba proses embuatan Telur Asin Dengan Menggunakan Pelepah Daun Nipah Sebagai media pengganti garam, Program Studi Perhotelan, Poli Teknik Bosowa, Jurnal Hospitality Dan Pariwisata Vol. 4 (no.1) : 1-69 Tahun 2018,ISSN :2441-5222. [6]

Roni Kastaman,Sudaryanto, Budi Herdi Nopianto,Kajian Proses Pengasinan Telur Metode Reverse Osmosis Pada Berbagai Lama Perendaman,Teknik Dan Manajemen Industry Pertanian, Fakultas Teknologi Industry Pertanian, Universitas Pajajaran, Bandung [7]

Dari penelitian-penelitian terkait yang pernah ada,dapat disimpulkan bahwa waktu pengasinan telur paling cepat 1-2 hari dengan tekanan udara yang telah ditentukan yaitu $1,5 \mathrm{~kg} / \mathrm{cm}^{2}$. Dan penelitian yang lain menggunakan asam cuka dengan berbagai konsentrasi tertentu untuk membuka semipermeable telur cara ini bisa mempercepat pengasinan telur hingga 3 jam.

Dengan adanya konsep ini penulis menyimpulkan bahwa suatu konsep baru dalam meningkatakan waktu produksi telur asin hingga 1-2 jam, karena konstruksi alat ini dirancang dengan menggunakan standard ASME dengan refrensi GUIDEBOOK, For The Design of ASME Section VIII Pressure Vessel,dan Pressure Vessel Handbook. Dengan aplikasi material mengacu kepada Standard aplikasi untuk makanan, dengan dibuatnya alat ini dengan menggunakan standard yang baku dimana alat ini harus di uji hingga tekanan pneumatic hingga 1,2 x MAWP (Maximum Allowable Working Pressure) dan material harus dilakukan uji komposisi kimia, ini adalah salah satu indikator bahwa alat ini safety dan sehat, dengan konstruksi yang kuat maka dapat dipastikan alat ini bisa manahan tekanan sesuai dengan desain awal, dimana fungsi tekanan ini adalah untuk mengatur proses abosrption larutan garam kedalam telur, proses percepatan produksi telur asin sangat tergantung dari pemberian tekanan pada Pressure Vessel dimana penelitian sebelumnya menggunakan material baji galvanis dan tidak disebutkan standard konstruksi pembuatannnya.

\section{METODE PENELITIAN}

2.1 Desain Alat Pembuatan Telur Asin Dengan Menggunakan Optimalisasi Compressed Air, seperti terlihat pada gambar 1 . 


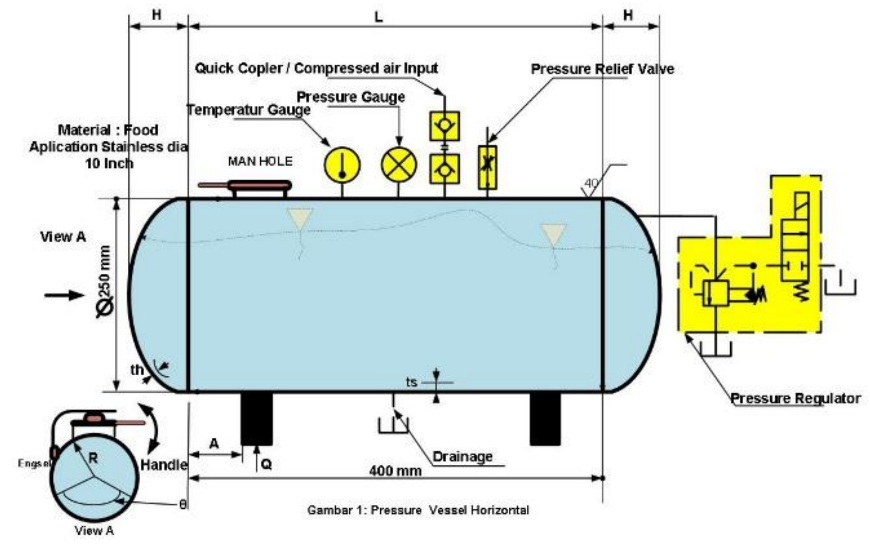

Gambar 1. Alat Pembuat Telur Asin

Dengan spesifikasi sebagai berikut :

Desain pressure 4 bar, MAWP 4 bar, Type Horizontal, material Stainless steel 304L, Test Pressure 4,8 bar, dan Accesories yang digunakan adalah:

\section{Temperatur Gauge \\ 2.Pressure Gauge \\ 3.Pressure Relief Valve \\ 4.Pressure Regulator \\ 5.Drainage Valve}

Alat ukur lain yang digunakan dalam proses produksi adalah Refractory yaitu alat ukur derajat keasinan, stop watch. Salah satu dasar pertimbangan menggunakan Compresses Air sebagai pemilihan proses percepatan waktu produksi adalah karena compressed air salah satu media yang bisa direkayasa dalam peningkatan tekanannya (compressible) tergantung kebutuhan dimana proses absorption kadar garam kedalam telur akan sangat cepat, dari sini dapat diambil kesimpulan bahwa dapat disesuai kan dengan melakukan variasi tekanan compressed air dan holding waktu, rencana variasi waktu adalah dimulai dari 0,5 bar, 1bar, 1,5 bar, 2 bar dan 3 bar. Dan dilakukan holding sesuai kebutuhan, Adapun metode penelitian dengan langkah sebagai berikut:

1. Mempelajari proses pembuatan telur asin baik yang dilakukan dengan cara tradisional maupun penelitian-penelitian tentang peningkatan produksi telur asin yang telah dilakukan, maupun standar-satndar dalam pembuatan konstruksialat yang aman dan sehat untuk meningkatkan waktu produksi.

2. Melakukan kalkulasi sesuai dengan standard

3. Melakukan proses manufaktur dan melakukan uji kinerja alat untuk melihat kekuatan konstruksinya.

4. Melakukan proses produksi telur asin, dengan melakukan Penyiapan telur, melakukan quality control kualitas telur, proses pembersihan telur, membuatan cairan garam hinga $2 / 3$ volume pressure vessel dan pemasakan hingga homogen, pemasukan telur kedalam pressure vessel, pemberian tekanan compressed air, percepatan produksi dilakukan dengan menaikan tekanan Compressed Air, kemudian telur dikeluarkan sesuai dengan waktu dan tekanan yang telah ditentukan, Kemudian derajat keasinan diukur dengan menggunakan alat Refraktometer ATC.Apabila tingkat keasinan telur belum tercapai maka akan dilakukan menaikan tekanan Compressed Air hingga mencapai tingkat keasinan yang diinginkan.

Untuk menguji kekuatan Pressure Vessel akan dilakukan uji kinerja alat dengan metode Pneumatic Test dengan mengacu pada Standard ASME UW-50 dengan 1,2 x MAWP (Maximum Allowable Working Pressure) sesuai dengan MDMT (Minimum Desain Metal Temperatur), setelah uji kinerja alat dilakukan selesai dan dinatakan baik maka dilakukan pembuatan air garam dengan perbandingan 12 biji telur bebek dengan 500 gram garam dan 1,5 liter air atau sesuai kebutuhan kemudian di masak sesuai kebutuhan, kemudian air garam didinginkan hingga temeperatur ruang dan dimasukan kedalam pressure vessel ,Cara Praktis Membuat Telur Asin Dengan air garam.[7]

Lakukan pengecheckan kualitas telur dengan jalan memasukan telur kedalam air, telur mengambang menandakan kualitas telur jelek, pisahkan telur yang sudah erindikasi jelek. Kemudian bersihkan telur dari kotoran yang menempel dengan lap dan menggunakan amplas hingga pori-pori telur terbuka. setelah itu telur dimasukan ke pressure vessel.

Kemudian tutup rapat man hole pada bagian atas, kemudian isi pressure vessel menggunakan Compressed Air (udara bertekanan) dengan tekanan bertahap untuk menghindari kerusakan alat ukur, dan hold dengan waktu 1 jam, 2 jam, 3 jam dan 4 jam dengan tekanan $2-3$ bar. Catat semua variable, tekanan, temperatur, waktu. Setelah itu selesai keluarkan telur dan ukur kadar garam yang terdapat pada telur dengan menggunakan Digital Water Salt Salinity Meter. Tahapan penelitian dapat dilihat seperti diagram alir dibawah : 

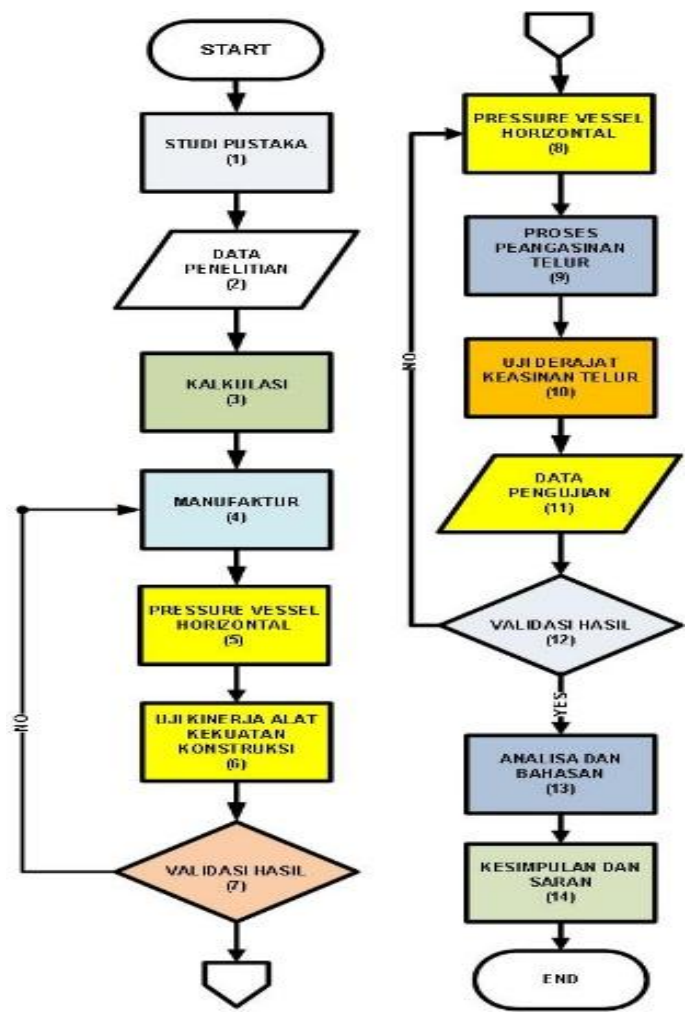

Gambar 1: Diagram Alir Penelitian

Rumus - rumus yang digunakan dalam konsep perancangan alaat sebagai berikut :

\section{Cylindrical Sheel long seam}

Dimana :

$$
t=\frac{P R}{S E+0,4 P}
$$

$\begin{array}{ll}\mathrm{t}: \text { tebal dinding sheel } & (\mathrm{mm}) \\ \mathrm{P}: \text { Tekanan } & (\mathrm{bar}) \\ \text { R:Radius } & (\mathrm{mm}) \\ \text { E:Effisiensi Sambungan } & \end{array}$

\section{Ellipsoidal Head}

Dimana :

$$
t=\frac{P D}{2 S E+1,8 P}
$$

$\mathrm{t}$ : Tebal dinding head $(\mathrm{mm})$

P: Tekanan (bar)

D: Diamater luar Head ( $\mathrm{mm}$ )

E: Effisiensi sambungan

\section{Longitudinal Bending Stress}

$$
Q A\left(1-\frac{\overline{\mathrm{L}}+\frac{\mathrm{R}^{2}-\mathrm{H}^{2}}{2 \mathrm{AL}}}{1+\frac{4 \mathrm{H}}{3 \mathrm{~L}}}\right)
$$

Dimana : Q: Beban sadle

R: Radius sheel

$\mathrm{S}$ : Tegangan

ts: Tebal dinding sheel

th: Tebal dinding head

$\mathrm{K}$ : Konstanta rasio A dan $\mathrm{R}$

$\Theta$ : Kontak sudut sadle

\section{Tangensial Shear}

4.1 Sadle pada Sheel

$$
\mathrm{S} 2=\frac{K 2 Q}{R t s}+\left(\frac{(L-2 A)}{L+\frac{4}{3} H}\right)
$$

Dimana : S2: Tegangan

K2: Konstanta

Q:Beban sadle

R: Radius Sheel

L : Panjang antar head

A: Jarak Sadle ke Head

$\mathrm{H}:$ Panjang Head

\subsection{Sadle ke Head}

$$
\mathrm{S} 2=\frac{K 4 Q}{R t s}
$$

Dimana : S2 : Tegangan tidak boleh lebi dari $0,8 \mathrm{x}$ nilai tegangan izin Material

K4: Konstanta

R: Radius Sheel

ts: Tebal dinding sheel

\section{Circumferential}

\subsection{Sadle}

$$
\mathrm{S} 4=-\frac{Q}{4 t s(b+1,56 \sqrt{R t s}}-\frac{3 K 6}{2 t s^{2}}
$$

\section{Dimana :}

S4: Tegangan tidak boleh lebih dari $1,5 \mathrm{x}$ tegangan tarik material sheel.
Q: Beban
K: Konstanta

\subsection{Dibawa Sheel}

$$
\mathrm{S} 5=-\frac{K 7 Q}{t s(b+1,56 \sqrt{R t s}}
$$

Dimana : S5 : Tegangan tidak boleh melebihi 0,5 x tegangan yield dari material

K: Konstanta

Ts : Tebal dinding sheel

$\mathrm{R}$ : Radius sheel 


\section{HASIL DAN PEMBAHASAN}

Dari desain konsep yang telah dibuat, didapat data sebagai berikut:

1. Konstruksi di desain sesuai standrad ASME, hal ini memungkinkan untuk menaikan tekanan compressed air hingga MAWP untuk mempercepat waktu proses produksi.

2. Material yang digunakan adalah Stainless Steel dengan jenis food aplication, hal ini telur yang dihasilkan terhindar dari cemaran / terkorosi.

3. Alat kontrol menggunakan sistem aplikasi teknologi pneumatic, seperti : Pressure regulator, Relief valve, Quick Copler, Pressure gauge dan Temperatur control. Hal ini berpengaruh terhadap kesetabilan tekanan compressed air, sehingga kualitas telur dengan keasinan yang merata.

Dari data tersebut dapat dikatakan bahwa konsep desain alat pembuat telur asin berbeda dengan penelitian yang lain dimana penelitian sejenis menggunakan tabung vertikal dengan bahan tabung Galvanis.

Sedangkan material yang digunakan dalam penelitian ini adalah stainless steel dengan jenis food aplication proses desig vessel menggunakan standard ASME Sec VIII, sedangkan kekuatan sambungan las menggunakan standard ASME sec IX, dimana untuk untuk proses penyambungan material dalam pembuatan pressure veseel mengacu kepada ASME Sec IX, dengan demikian kekuatan dan keamanan vessel akan lebih terjamain. Hal ini sangat penting dilakukan agar para produksi penggiat telur asin yang umumnya tidak paham teknologi, akan lebih aman, dan sehat, disamping itu penelitian ini bertujuan untuk menerapkan hasil rangcangan yang memperhatikan faktor-faktor keamanan bagi lingkungan, aset dan manusia.

\section{KESIMPULAN DAN SARAN}

Dari hasil kajian diatas dapat disimpulkan bahwa konsep alat pembuat alat telur asin ini apabila diterapkan akan memperpendek waktu pengasinan telur hingga $1-2$ jam dan dapat dikatan lebih safety dan sehat bagi lingkungan karena perancangan konstruksi dan uji kinerja menggunakan standard ASME

\section{UCAPAN TERIMA KASIH}

Dalam kesempatan ini saya ucapkan banyak terimakasih kepada Staf dan dosen Laboratorium Research Mekanika Struktur, yang telah banyak memberiakn masukan dalam perancangan konsep ini dengan segala keterbatasan akibat wabah Covid - 19.

\section{REFERENSI}

Andriani D., Hadijah S.(2018). Uji Coba Pembuatan Telur Asin Dengan Menggunakan Pelepah Daun Nipah Sebagai Pengganti Garam, Jurnal Hosfitality dan Pariwisata, Vol 4 No. $1: 1-69$ Th 2018, ISSN 2442- 5222.

ASME Boiler and Pressure Vessel Code Sec IX, Welding and Brazing Qualification,2004.

Engelen A., Umela S., Hasan AA., (2017). Pengaruh Lama PengasinanPada Pembuatan Telur Asin Dengan Cara Basah,Jurnal ArgoIndustri Halal, ISSN 2442-3548, Volume 3 Nomor 2, Februari 2017, 133

Farr JR., Jawad MH. (2001). Guidebook For The Design Of ASME Section VIII Pressure Vessel, Second Edition, ASME Press, New York.

Kastaman R., Sudaryanto, Nopianto BH. (2005). Kajian Proses Pengasinan Telur Metode Revese Osmosis Pada Berbagai Lama Perendaman, J.Tek.Ind.Pert Vol.19.(1) 30-39

Megyesy EF.(2004). Pressure Vessel Handbook, Thirteenh Edition, Pressure Vessel Publishing, Inch, Date of Issuance: November 15.

Peckner D.,.Bernstain IM. (1977). Handbook of Stainless Steel, McGraw-Hill Book Company.

Sunyoto, Suwahyo, Putri M.F. (2015). Penerapan IPTEK Pada Industry Kecil Pembuatan Telur Asin Khas Tambakrejo Kota Semarang, Rekayasa Vol 13 No.2 Juli 2015.

Susanto TA., Razak AK.,Asywar, Suryaningsih M., Syamsul. (2016). Rancang Bangun Alat pembuat Telur AsinDengan Pemanfaat Udara: Jurnal Teknik Mesin Sinergi, Jurusan Teknik Mesin , Politeknik Negeri Ujung Pandang, Beranda, Vol 14,No.1.

Susilo J., Teknologi Pembuatan telur asin Selama Tiga Jam Melalui Manifulasi tekanan Osmosisi, SMA Negeri 1 Plupuh Sragen. 